\title{
Is evolutionary science in conflict with Adam and Eve?
}

Daniel Gordon Ang (D), Jon Garvey (1), David Kwon and S. Joshua Swamidass (1)

https://doi.org/10.54739/qg9m

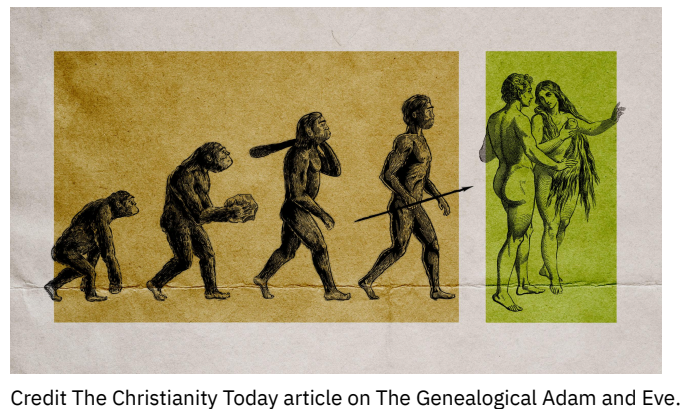

Credit The Christianity Today article on The Genealogical Adam and Eve. s evolutionary science in conflict with Adam and Eve?

Christians throughout history have understood Adam and Eve as the "first man and woman" created in the image of God and placed in the Garden of Eden (Genesis 1:26-28, 2:4-25). But today, people commonly think that Adam and Eve are incompatible with modern evolutionary science.

On the one hand, some reject evolutionary science, while affirming the Genesis account of human origins.

On the other hand, others reject Adam and Eve as real people in a real past, while affirming the evolutionary account of human origins.

However, this is a false dichotomy. Critically, there is nothing in evolutionary science that conflicts with a historical Adam and Eve who are ancestors of us all. It turns out that there are a wide range of ways to understand Adam and Eve in light of science, Scripture, and theology, including both historical and non-historical views. Some of these possibilities have only recently been realized as viable options.

In fact, there are so many ways to understand Adam and Eve that it is difficult to classify all of the different models that have been proposed. Nonetheless, we find the following four questions to be a helpful starting point:

1. Were Adam and Eve real people in a real past?

2. Which models of Adam and Eve are consistent with evolutionary science?

3. Do Adam and Eve sit at the headwaters of humanness?

4. Were Adam and Eve created de novo without parents?

There are a multitude of ways to understand Adam and Eve that are consistent with modern science. Even traditional commitments about Adam and Eve need not be in conflict with evolution.

\section{Were Adam and Eve real people in a real past?}

Some scholars have proposed that Adam and Eve are literary figures that are purely mythical or archetypal. ${ }^{1}$ The Adam and Eve narrative bears striking similarities to the Akkadian Atrahasis epic as well as many other Sumerian, Babylonian, and Egyptian texts. ${ }^{2}$ For this reason (and several others), these scholars understand the narrative

1. Enns (2012). Other notable figures in this camp include Daniel Harlow (2010), Denis Lamoureux (2009; 2013), Karl Giberson (2008:11-12), Alister McGrath, and J. Richard Middleton (2017). as only trying to teach theological truths, without reference to historical events or historical figures. ${ }^{3}$ God was simply accommodating his word to the language familiar to ancient readers. A view like this would readily remove any conflict with science, simply because it no longer views Genesis 2-3 as saying anything about realworld events.

Other scholars remain unpersuaded by these arguments. C. John Collins argues that in light of the overarching narrative of the Old Testament, the Genesis 1-11 narrative must retain a historical core, even if it contains special rhetoric and literary techniques to shape the descriptions of the events. ${ }^{4}$ In addition, other theological concerns may make a historical Adam and Eve necessary, such as maintaining the uniqueness of human beings as made in the image of God, the unity of all humans, a historical Fall from original sinlessness, and the doctrine of original $\sin ^{5}$

\section{Which models of Adam and Eve are consistent with evolutionary science?}

If we want to affirm that Adam and Eve were real people who existed in the past, how are we to make sense of that in light of the modern scientific description of human origins? According to evolutionary science, humans share common ancestry with the great apes. ${ }^{6}$ These and other discoveries have led scientists to conclude that anatomically modern humans emerged several hundred thousand years ago in Africa from an evolutionary process.

Young earth creationists (YECs) choose to resolve this question by rejecting evolutionary science and common ancestry, understanding Adam and Eve to be the first two biological humans created de novo no more than $6,000-10,000$ years ago. ${ }^{7}$ While some YEC scholars

2. Enns (2012:53-55).

3. Harlow (2010) argues that other features of the narrative indicate non-historicity, such as irreconcilable differences between the two creation accounts of Gen. 1:1-2:3 and 2:4-25, an anthropomorphic picture of God, resemblance of features of the Garden Eden with the desert tabernacle and Jerusalem temple, and the character of the talking snake.

4. Collins (2011, chs. 2-3; 2013).

5. Grudem (2017) criticizes theistic evolutionary models (which may not affirm a historical Fall or reject monogenesis) as jeopardizing the notion of Christ's representation of believers which leads to their forgiveness and redemption. Another common objection is that without a historical Adam, Paul's arguments in Romans 5 and 1 Corinthians 15 would not make sense (Reeves 2011).

6. More technical overviews of the evidence for common ancestry include Baum et al. (2016). 
have offered alternative accounts of how such a view could fit with the scientific evidence, ${ }^{8}$ these models are unconvincing to the vast majority of scientists, including even the vast majority of Christian scientists. ${ }^{9}$

Thus, there are two extremes: young earth creationism and a nonhistorical Adam and Eve. The first is in conflict with how most scientists understand the evidence. The second deviates from how most Christians have understood Scripture.

But these two views do not exhaust all possibilities. Several models of Adam and Eve were previously thought to conflict with the scientific evidence, but turn out to be entirely consistent with it.

For example, it is possible for Adam and Eve to have been supernaturally created a few thousand years ago in the Middle East and become universal genealogical ancestors of us all, a model which was recently proposed by biologist Joshua Swamidass. ${ }^{10}$ Another alternative is to understand Adam and Eve as living several hundred thousand years ago. Fazale Rana and Hugh Ross of Reasons to Believe propose that Adam and Eve were the first Homo sapiens and lived 100,000-200,000 years ago, whose descendants interbred with Neanderthals to account for the observed genetic diversity among today's humans. ${ }^{11}$ Finally, philosopher and theologian William Lane Craig favors an even more ancient Adam, identifying Adam and Eve as Adam and Eve as two members of the species Homo heidelbergensis, which existed starting about 700,000 years ago. ${ }^{12}$

\section{Do Adam and Eve sit at the headwaters of humanness?}

An important doctrine in the Christian understanding of humanity is monogenesis, the idea that all humans are descended from a single couple. ${ }^{13}$ Some scholars have argued that monogenesis serves as the

7. We use the term de novo to mean that Adam and Eve were created instantly and supernaturally "out of the dust" without biological parents, instead of through purely natural processes.

8. Sanford and Carter (2018) is an example.

9. In fact, some young earth creationists such as Todd Wood admit that evolution is an "extremely successful scientific theory."

10. The key here is understanding the difference between genetic and genealogical ancestry, making a distinction between "humans according to science" and "humans according to Scripture", and allowing the possibility that Adam and Eve's descendants interbred with humans outside the Garden. Genealogical ancestry spreads rapidly in time, such that anyone living a few thousand years ago who left a reasonable number of grandchildren would be the ancestors of everyone living today. See Swamidass (2019, especially chapter 14) or this blog post (Story Three) for a shorter overview. Other scholars who have proposed similar models include Andrew Loke (2016) and Kenneth Kemp (2011).

11. See Rana and Ross (2015) for a more detailed account of this model. Note that there have been multiple versions of the RTB model to take into account new scientific evidence. See this blog post and this discussion thread for more details. An even more ancient Adam is suggested by philosopher and theologian William Lane Craig, who identifies Adam and Eve as two members of the Homo heidelbergensis, a species which existed starting about 700,000 years ago. As current genetic evidence cannot detect bottlenecks in the human population older than about 500,000 years ago, this model is also consistent with the scientific evidence.

12. See also the upcoming book by Craig (2021).

13. Biblical passages often cited in support of this doctrine are Acts 17:26 ("And he made from one man every nation of mankind to live on all the face of the earth") and Romans 5:12-19, where Paul argues that just as sin and death entered the world from one man (Adam), it is redeemed by the actions of one man (Jesus). foundation for equality between all nations and races, as well as the universal common experience of being fallen and in need of redemption. ${ }^{14}$ Monogenesis is one of the commonly cited reasons for retaining a historical Adam and Eve.

But for a long time, most thought that there was a dilemma between (1) monogenesis and (2) a recent Adam and Eve. In other words, evolution and modern science forces us to choose between either:

1. Adam and Eve living recently (less than 10,000 years ago), but not ancestors of us all.

2. Adam and Eve as ancestors of us all, but living in the ancient past (over 100,000 years ago).

Some argued that this last option was also in conflict with the evidence. ${ }^{15}$ In this way, traditional readings of Genesis and traditional doctrine were thought to need revision due to an irresolvable conflict with science. $^{16}$

However, it turns out that this is a false dilemma, based on a mistaken understanding of the scientific evidence. As we have mentioned above, even if Adam and Eve were as recent as 6,000 years ago, we all could descend from them. ${ }^{17}$ So the dilemma between a recent Adam and Eve and monogenesis is resolved.

Still, some prefer to think that Adam and Eve were ancient. ${ }^{18}$ The salient point here is whether or not there were beings with "humanlike" qualities or "humanness" outside the Garden and before Adam and Eve. ${ }^{19}$ If one believes that these human-like beings need to descend from Adam and Eve, then the first couple would have to be placed further back in history. ${ }^{20}$ This shows how the debate between a recent and ancient Adam and Eve revolves around interesting questions about what truly defines human behavior. It is not always the case that theologians and biblical scholars are interested in the same questions as modern scientists.

\section{Were Adam and Eve created de novo or chosen?}

Historically, most thought that if evolutionary science were true, then Adam and Eve could not have been created de novo without parents. ${ }^{21}$ However, this is another false dilemma. Both could be true at the same time. ${ }^{22}$ God could have created a population by a process

14. Collins (2011, sections 3e and 4b). See also Beeke (2015).

15. For example, see McKnight and Venema (2017).

16. To make matters worse, some argued that even an ancient Adam and Eve could not be ancestors of us all. This also turned out to be false, as current scientific methods cannot detect bottlenecks older than about 500,000 years ago (see note 11). The RTB model is also a viable alternative (see the previous section and note 10).

17. See note 10 above regarding the recent Adam and Eve model proposed by Swamidass.

18. As in the RTB and Craig models.

19. Paleoanthropologists observe evidence of human-like behavior reaching back to at least the Upper Paleolithic period (10,000-40,000 years ago) and even earlier.

20. On the other hand, we encounter no such need if we believe that Adam and Eve were special because of their theological and vocational status, rather than being the first on Earth who possess unique behavioral and cognitive abilities. Another alternative is to posit that after Adam and Eve were created, there was a way for people outside the Garden to become represented by Adam and Eve, as in the models of Derek Kidner (2008:28-30) and Denis Alexander (2014:289-294, 300-304). 
of common descent, and then specially created a couple within that population. A one-off, isolated miraculous scenario cannot be falsified by scientific evidence, just as many Christians would agree that the resurrection of Jesus is not "falsified" by the empirical evidence that people normally do not rise from the dead. ${ }^{23}$

If one affirms evolutionary science, why still believe in de novo creation? Some, like pastor Tim Keller, believe that it is necessitated by the text of Genesis $2 .{ }^{24}$ De novo creation may also be required if one commits to a particular view of the image of God or to establish some sort of original moral righteousness in Adam and Eve which cannot be achieved by natural processes alone. ${ }^{25}$

\section{What questions remain?}

The four key questions we have covered help to illuminate the many possible understandings of Adam and Eve. However, they hardly exhaust the range of questions and issues that are raised in these

21. Until recently most scholars who proposed a historical Adam and Eve while affirming evolutionary science tended to assume that they must have been chosen from a pre-existing population of hominids. This is the case for the models by Alexander, Kidner (see note 17), Kemp, and John Walton (2015, Proposition 21).

22. Swamidass (2019, chapter 7).

23. Other objections to de novo creation are discussed in Swamidass (2019:85-89). See also these forum threads for additional discussion.

24. This also seems to be the view of Wayne Grudem.

25. This forum thread may be a useful discussion on other reasons for why de novo creation is important. discussions. Different models may answer certain questions more clearly while raising others. Here are some examples:

1. In recent Adam and Eve models, how are we to understand the theological status of people outside the Garden? Do they possess the image of God? ${ }^{26}$

2. How do different understandings of the image of God interact with different models of Adam and Eve ${ }^{27}$

3. How does an ancient Adam fit with biblical genealogies which may establish a connection between Adam and Israel ${ }^{28}$

4. How do we understand original sin and the Fall in each of these models?

Many of these questions do not yet have definite answers. They remain an open invitation for theologians, scientists, and anyone else interested in the conversation. We should know not to expect easy solutions. Nor should we prematurely leap to simplistic narratives of "conflict" or "harmony" between science, Scripture, and theology. In the end we are all approaching a grand question that makes this conversation captivating and important: what does it mean to be human?

26. Some of these questions are tentatively explored in chapters 14-16 of Swamidass book.

27. There are several different major understandings of the image of God, such as the structural and vocational/relational understandings (Collins 2011, section 4a).

28. Garvey (2020:147-155). While gaps in ancient genealogies are possible, gaps of tens of thousands of years (as what must be the case if Adam lived several hundred thousand years ago) make them practically meaningless.

edited by J. P. Moreland, S. C. Meyer, C. Shaw, A. K. Gauger, and W. Grudem. Crossway.

Harlow, Daniel C. 2010. "After Adam: Reading Genesis in an Age of Evolutionary Science.” Perspectives on Science and Christian Faith 62(3):17

Kemp, Kenneth W. 2011. “Science, Theology, and Monogenesis.” American Catholic Philosophical Quarterly 85(2):217-36).

Kidner, Derek. 2008. Genesis: An Introduction and Commentary. IVP Academic/Intervarsity Press.

Lamoureux, Denis O. 2009. Evolutionary Creation: A Christian Approach to Evolution. ISD LLC.

Lamoureux, Denis O. 2013. “No Historical Adam: Evolutionary Creation View." in Four Views on the Historical Adam, edited by M. Barrett and A. B. Caneday. Zondervan Academic.

Loke, Andrew Ter Ern. 2016. “Reconciling Evolution and Biblical Literalism: A Proposed Research Program.” Theology and Science 14(2):160-74. doi: 10.1080/14746700.2016.1156328.

McKnight, Scot, and Dennis R. Venema. 2017. Adam and the Genome: Reading Scripture after Genetic Science. Brazos Press.

Middleton, J. Richard. 2017. "Humans as Imago Dei and the Evolution of Homo Sapiens - Articles.” BioLogos. Retrieved November 14, 2020 ( https://biologos.org/articles/humans-as-imago-dei-and-the-evolutionof-homo-sapiens/).

Rana, Fazale, and Hugh Ross. 2015. Who Was Adam?: A Creation Model Approach to the Origin of Man. RTB Press.

Reeves, Michael. 2011. “Adam and Eve.” in Should Christians Embrace Evolution?: Biblical and Scientific Responses, edited by N. C. Nevin. P \& R Publishing Company. 
Sanford, John, Robert Carter, Wes Brewer, John Baumgardner, Bruce Potter, and Jon Potter. 2018. "Adam and Eve, Designed Diversity, and Allele Frequencies." The Proceedings of the International Conference on Creationism 8(1):200-216. doi: 10.15385/jpicc.2018.8.1.20.
Swamidass, S. Joshua. 2019. The Genealogical Adam and Eve: The Surprising Science of Universal Ancestry. InterVarsity Press.

Walton, John H. 2015. The Lost World of Adam and Eve: Genesis 2-3 and the Human Origins Debate. InterVarsity Press. 